\title{
Correlation of Body Mass Index with Handgrip Strength and Endurance of Dominant Hand in Medical Students
}

\author{
Lava Shrestha', Sanyukta Gurung ${ }^{1}$, Neeti Bhat ${ }^{2}$, Narayan B Mahotra', Mahesh M Bajimaya', Neha \\ Malla', Sabita Kandel', Aman Shakya', Vibina Aryal', Bigyan R Gyawali', Nirmala Rayamajhi', \\ Sait Pradhan ${ }^{1}$ \\ 1Department of Clinical Physiology, Maharajgunj Medical Campus, Tribhuvan University Teaching Hospital, \\ Institute of Medicine, Maharajgunj, Kathmandu, 'Madan Bhandari Academy of Health Sciences, Hetauda, \\ ${ }^{3}$ Department of Physiology, National Medical College \& Teaching Hospital, Birgunj, ${ }^{4}$ Department of ENT, Head \\ \& Neck Surgery, Maharajgunj Medical Campus, Ganesh Man Singh Memorial Academy of ENT - Head \& Neck \\ Studies, Tribhuvan University Teaching Hospital, Institute of Medicine, Maharajgunj, Kathmandu, ${ }^{5} \mathrm{Nepal}$ Police \\ Hospital, Maharajgunj, Kathmandu.
}

\section{Corresponding author:}

Mahesh M Bajimaya, MBBS, MD

Department of Clinical Physiology, Maharajgunj Medical Campus, Institute of Medicine, Maharajgunj, Kathmandu, Nepal

Email: bajimayamahesh@gmail.com

Submitted : Sept 16, 2020

Accepted : Nov 26, 2020

\begin{abstract}
\section{Introduction}

Hand grip strength is used in evaluation of muscle strength and is also increasingly being used as an indicator for nutritional status. The maximum force applied voluntarily by the subject is called maximum handgrip strength, which is measured in kilograms. Muscular endurance is the ability of a muscle or muscle group to perform against a load for an extended period of time, measured in seconds. This study aims to correlate body mass index with handgrip strength and handgrip endurance in medical students.
\end{abstract}

\section{Methods}

This is a cross sectional, observational study which included 74 undergraduate students of Maharajgunj Medical Campus by convenient sampling method. Body mass index was calculated by Quetelet's formula. Camry digital hand dynamometer was used to measure handgrip strength in the dominant hand in kilograms. Participants were instructed to hold dynamometer with maintained pressure of $30 \%$ of maximum handgrip strength for as long as possible to determine the handgrip endurance. Statistical analyses were performed with SPSS Statistics software.

\section{Results}

The handgrip strength was more in males than females with a mean of $43.09 \pm 3.72 \mathrm{~kg}$, while handgrip endurance was more in females with a mean of $123.60 \pm 50.65 \mathrm{sec}$. Positive correlation was seen between body mass index and handgrip strength $(r=0.23$ and $p=0.045)$. Body mass index and handgrip endurance also showed positive correlation $(r=0.34$ and $p=0.003)$.

\section{Conclusion}

Significant correlation of body mass index with handgrip strength and handgrip endurance was seen in medical students.

Keywords

Body mass index, correlation, handgrip endurance, handgrip strength, medical students 


\section{INTRODUCTION}

$\mathrm{O}$ besity is becoming more prevalent and has almost tripled from 1975 to 2016 worldwide. Excessive fat accumulation that could put our health at risk is overweight and obesity. ${ }^{1}$ Obesity and overweight is in the up rise with malnutrition still prevailing in a developing country like Nepal. ${ }^{2}$ Factors affecting obesity and overweight deals with the disproportionate consumption and expenditure of calories. The increasing consumption of energy dense diet which contains high fat and the sedentary life style due to increase in desk bounded form of work, easy accessibility to transportation are leading to a rise in obesity and overweight. ${ }^{1}$

Hand grip strength (HGS) is used in evaluation of muscle strength and is also increasingly being used as an indicator for nutritional status. ${ }^{3}$ The result produced by forced flexion of all finger joints with maximum force applied voluntarily by the subject is called maximum handgrip strength, which is measured in kilograms. ${ }^{4}$ Muscular endurance is the ability of a muscle or muscle group to perform against a load for an extended period of time, measured in seconds. The strength of the grip is affected by various factors like age, gender, restricted range of motion, nutritional status, muscular strength, pain and fatigue. ${ }^{5}$ There is a change in muscle quality with change in body mass index (BMI). The decrease in muscle strength and endurance in underweight and obese subjects can be interpreted as alteration in muscle quality. 6,7 This study aims to correlate BMI with hand grip strength and endurance of dominant hand.

\section{METHODS}

This is a quantitative, cross sectional, observational study. The study was conducted in the Department of Clinical, Physiology of Maharajgunj Medical Campus from June to November of 2020 after obtaining ethical approval from Institutional Review Committee (IRC) of Institute of Medicine, Tribhuvan University. Purposive sampling was done and sample size was calculated using $G^{*}$ power software. Effect size was calculated taking $r^{1}=$ 0.463 and $r^{2}=0.097$ from the study conducted by Oseloka et al. ${ }^{6}$ Sample size was calculated and adjusted to 74 undergraduate students. Undergraduate students from the age 18 to 24 years that included 37 males and 37 females were enrolled in the study after obtaining written informed consent. Physical Activity Readiness Questionnaire (PAR-Q) was used and body builders, subjects with musculoskeletal, neurological, cardiovascular and respiratory disorders were excluded. Height was recorded in centimetres and weight in kilograms. BMI was calculated using Quetelet's formula weight in kilograms/height in meter $^{2}$.

Participants were requested to hold the Camry digital hand dynamometer by dominant hand with elbow at 90 degrees and apply maximum pressure for three seconds. The measurements were recorded in kilograms and procedure was repeated three times with an interval of 30 seconds. Maximum value was used as the maximum handgrip strength.

After an interval of one minute participants were requested to hold the dynamometer with maintained pressure of 30 percent of maximum handgrip strength for as long as possible. Time was recorded in seconds with a stopwatch. IBM SPSS software version 23 was used for statistical analysis. For categorical variable frequency was calculated. Mean and standard deviation was calculated for continuous variables. Correlation of BMI with handgrip strength and handgrip endurance was interpreted by Pearson's correlation test and p-value of less than 0.05 at $95 \%$ confidence interval was considered statistically significant.

\section{RESULTS}

Among the total of 74 participants there, were 37 males and 37 females. The mean age of the participants was $19.97 \pm 1.15$ years, mean BMI was $20.76 \pm 2.71 \mathrm{~kg} / \mathrm{m}^{2}$, mean handgrip was $34.24 \pm 9.72 \mathrm{~kg}$ and mean handgrip endurance was $113.45 \pm 44.61 \mathrm{~s}$. Handgrip strength was more in the male participants $(43.09 \pm 3.72 \mathrm{~kg}$ vs $25.39 \pm 4.10 \mathrm{~kg})$ whereas, handgrip endurance was more in the female participants $(123.60 \pm 50.65$ vs $103.30 \pm 35.48$ s) than in male participants (Table 1).

Majority of the participants were in normal weight category according to BMI. Thirty one males and

Table 1. Handgrip strength and endurance among males and females $(n=74)$

\begin{tabular}{|c|c|c|c|c|c|c|}
\hline \multirow[b]{2}{*}{ BMI category } & \multicolumn{3}{|c|}{ Male $(n=37)$} & \multicolumn{3}{|c|}{ Female $(n=37)$} \\
\hline & $\mathrm{N}$ & $\begin{array}{c}\text { Handgrip } \\
\text { strength }(\mathrm{kg})\end{array}$ & $\begin{array}{c}\text { Handgrip } \\
\text { endurance (s) }\end{array}$ & $\mathrm{N}$ & $\begin{array}{c}\text { Handgrip } \\
\text { strength }(\mathrm{kg})\end{array}$ & $\begin{array}{c}\text { Handgrip } \\
\text { endurance (s) }\end{array}$ \\
\hline Underweight & 6 & $40.63 \pm 1.05$ & $89.00+34.50$ & 10 & $24.25 \pm 2.52$ & $105.60 \pm 46.47$ \\
\hline Normal & 31 & $43.57+3.87$ & $106.06 \pm 35.54$ & 23 & $25.26 \pm 4.56$ & $124.91 \pm 40.76$ \\
\hline Preobese & - & - & - & 4 & $29.00 \pm 2.87$ & $161.00 \pm 95.75$ \\
\hline Overall & 37 & $43.09 \pm 3.72$ & $103.30 \pm 35.48$ & 37 & $25.39 \pm 4.10$ & $123.60 \pm 50.65$ \\
\hline
\end{tabular}




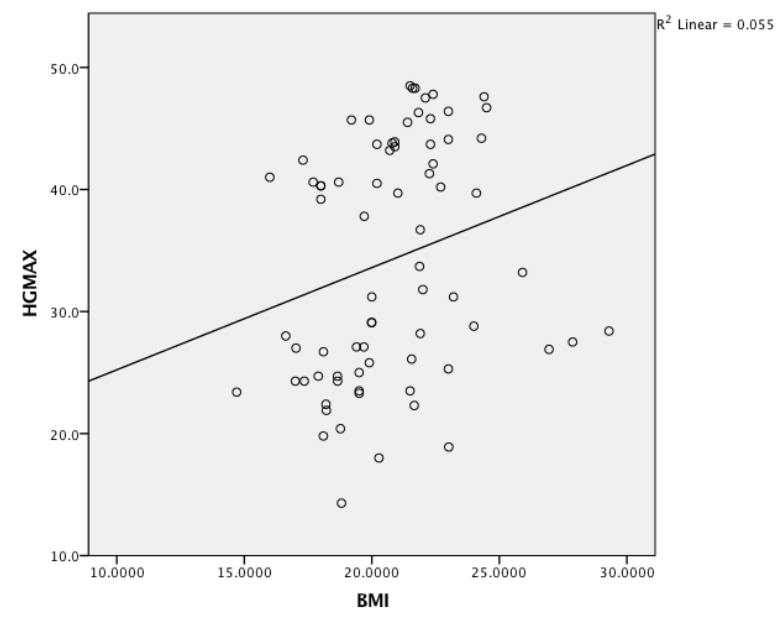

Fig 1. Scatterplot of BMI with handgrip strength

twenty three females were in the normal weight category. Four females were in the preobese category whereas none of the males were in the preobese category. Six males and ten females were underweight (Table 1).

The highest handgrip strength was observed in the normal BMI category for the male participants with a mean of $43.57 \pm 3.87 \mathrm{~kg}$ whereas, for the female participants the highest handgrip strength was observed among the preobese category with a mean of $29 \pm 2.87 \mathrm{~kg}$. The highest mean handgrip endurance was observed among the normal category with mean of $106.06 \pm 35.54 \mathrm{~s}$ for males whereas, highest mean handgrip endurance was observed in the preobese category among the females with a mean of $161.00 \pm 95.75 \mathrm{~s}$.

A significant correlation was seen between handgrip strength and $\mathrm{BMI}$ where the r-value was 0.23 and p-value was 0.045 (Figure 1). Similarly a significant correlation was seen between handgrip endurance and $\mathrm{BMI}$ with r-value of 0.34 and $p$-value of 0.003 (Figure 2).

A significant correlation was seen between $\mathrm{BMI}$ and handgrip strength among the female participants with r-value of 0.36 and p-value 0.03 among the female participants whereas, among the male participants r-value 0.32 and $p$-value was 0.06 .

Table 2. Correlation of BMI and handgrip strength among males and females $(n=74)$

\begin{tabular}{|c|c|c|c|c|c|c|}
\hline \multirow{2}{*}{$\begin{array}{c}\text { BMI } \\
\text { category }\end{array}$} & \multicolumn{3}{|c|}{ Male $(n=37)$} & \multicolumn{3}{|c|}{ Female $(n=37)$} \\
\hline & $N$ & $\begin{array}{c}r \\
\text { value }\end{array}$ & $\begin{array}{c}\mathrm{p} \\
\text { value }\end{array}$ & $\mathrm{N}$ & $\begin{array}{c}r \\
\text { value }\end{array}$ & $\begin{array}{c}\mathrm{p} \\
\text { value }\end{array}$ \\
\hline & 6 & -0.4 & 03 & 10 & -0.25 & 0.4 \\
\hline Norm & 31 & 0.17 & 0.37 & 23 & 0.30 & 0.17 \\
\hline Preobese & - & - & - & 4 & -0.58 & 0.42 \\
\hline
\end{tabular}

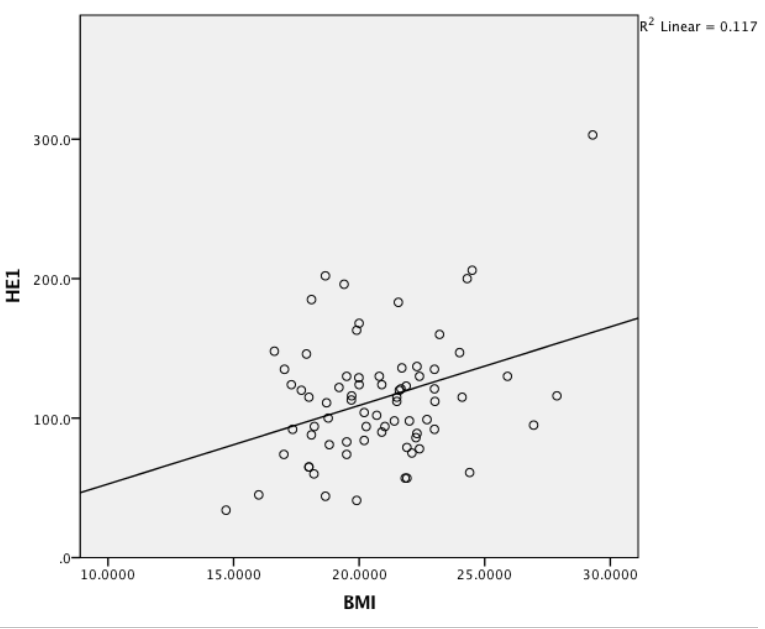

Fig 2. Scatterplot of BMI with handgrip endurance

A significant correlation was seen between $\mathrm{BMI}$ and handgrip endurance with r-value of 0.41 and $p$-value 0.01 among the female participants whereas, r-value for the male participants was 0.32 and p-value was 0.05 .

A negative correlation was seen between BMI handgrip strength in the underweight category for both male and female participants with r-value -0.48 and $p$-value 0.34 for males and r-value -0.25 and $p$-value 0.48 . A positive correlation was seen in both males and females in the normal weight category with r-value 0.17 and p-value 0.37 for males and r-value 0.30 and p-value 0.17 in females. There were no preobese male whereas, negative correlation was seen among the female participants with r-value -0.58 and p-value 0.42 .

A positive correlation was seen between underweight category and handgrip endurance for both male and female participants with r-value 0.40 ; $p$-value 0.43 and r-value 0.40 ; $p$-value 0.26 , respectively. A positive correlation was seen in both male and female participants in the normal weight category with r-value 0.29 and $p$-value 0.12 for male participants and r-value 0.17 , p-value 0.44 for female participants. A positive correlation was seen among the preobese participants with r-value 0.79 and p-value 0.22 .

Table 3. Correlation of BMI and handgrip endurance among males and females $(n=74)$

\begin{tabular}{|c|c|c|c|c|c|c|}
\hline \multirow{2}{*}{$\begin{array}{c}\text { BMI } \\
\text { category }\end{array}$} & \multicolumn{3}{|c|}{ Male $(n=37)$} & \multicolumn{3}{|c|}{ Female $(n=37)$} \\
\hline & $\mathrm{N}$ & $\begin{array}{c}r \\
\text { value }\end{array}$ & $\begin{array}{c}\mathrm{p} \\
\text { value }\end{array}$ & $\mathrm{N}$ & $\begin{array}{c}r \\
\text { value }\end{array}$ & $\begin{array}{c}\mathrm{p} \\
\text { value }\end{array}$ \\
\hline Underweight & 6 & 0.40 & 0.43 & 10 & 0.40 & 0.26 \\
\hline Normal & 31 & 0.29 & 0.12 & 23 & 0.17 & 0.44 \\
\hline Preobese & - & - & - & 4 & 0.79 & 0.22 \\
\hline
\end{tabular}




\section{DISCUSSION}

Similar to our study students in College of Medicine, Basrah also had a mean handgrip strength of $34.1 \pm 11.9 \mathrm{~kg}$ and the mean handgrip strength of males was $44.1 \pm 7.8 \mathrm{~kg}^{8}$ A study conducted in Hassan institute of Medical Sciences also had similar mean handgrip strength of $24.18 \pm 5.67 \mathrm{~kg}$ among the female participants. ${ }^{9}$ A study conducted in Konaseema Institue of Medicine Science also showed highest mean handgrip strength in the normal BMI category among the male participants with a mean of $33.33 \pm 2.58 \mathrm{~kg} .{ }^{10}$

In contrast to our study Australian population had a higher mean hand grip strength of $47 \pm 9.5$ in males and $30 \pm 7.11$ This variation could be explained by the genetic factor in different regions. ${ }^{12}$ Higher muscle strength in males can be explained by testosterone, which increases muscle size and strength. ${ }^{13}$ The variation in results may also be influenced by the methodology used in the study and different equipment used in different studies. ${ }^{14}$

Similar to our study handgrip endurance was seen higher in the overweigh category in a study done by Ravisankar et al. with a mean of $104 \pm 40$ s. ${ }^{15}$ In contrast to our study Lad et al. showed higher mean handgrip endurance among the normal BMI category with a mean of $199.73 \pm 29.09$ s among the male participants and $140.8 \pm 28.35$ s among the female participants. ${ }^{10}$

A study conducted by Al-Asadi also showed a significant correlation of handgrip strength and BMI with $r$ value 0.252 and a $p$-value $<0.005 .{ }^{8}$ In concordance to our study a significant positive correlation was seen between handgrip endurance and BMI in a study conducted by Dhananjaya et al. with a r-value of 0.24 and a p-value of $0.001 .{ }^{9}$ In similarity to our study, a study conducted by Liao observed a negative correlation between BMI and left handgrip strength with $r$-value $=-0.031$ and p-value $>0.05$ among the high BMl category. ${ }^{16} \mathrm{~A}$ negative correlation of $\mathrm{BMI}$ and handgrip strength was seen in the obese male participants in a study conducted by Dhananjaya et al. where r-value was -0.563 and $p$-value was $0.437 .^{9}$ A sudy conducted by Das et al. also showed $r$-value $=-0.346$ and $\mathrm{p}$-value $=0.047$ among the over weight female participants between BMI and handgrip strength. ${ }^{17}$

Better handgrip strength in the normal BMI category could be explained by the change in muscle quality with change in BMI. The decrease in muscle strength in underweight subjects can be interpreted by deficiency in energy. Fatty infiltration in the muscles and decrease in amount of type 1 red muscle fibers, slow oxidative and increase in type $2 b$ white muscle fibers fast glycolytic, fast fatigable in obese subjects could alter the muscle quality. ${ }^{7}$
This study was conducted in a single institute and does not represent the Nepalese population. It was a cross sectional study hence does not show the cause and effect. The influence of exercise and training have not been evaluated as well. Convenient sampling may have caused selection bias.

\section{CONCLUSION}

A significant correlation of BMI with handgrip strength and handgrip endurance was seen in this study. Male participants had better handgrip strengths whereas female participants had better handgrip endurance. A negative correlation was seen between BMI and handgrip strength in the underweight and overweight categories. A positive correlation was observed between handgrip endurance and all the BMI categories in both male and female participants.

\section{CONFLICT OF INTEREST}

None declared.

\section{REFERENCES}

1. World Health Organization. Obesity and Overweight. Obesity and Overweight. [Accessed 2019 Jun 16]. Available from: https://www. who.int/news-room/fact-sheets/detail/obesity-and-overweight

2. Jafar TH, Qadri Z, Islam M et al. Rise in Childhood Obesity with Persistently High Rates of Undernutrition Among Urban SchoolAged Indo-Asian Children. Arch Dis Child. 2008 May;93(5):373-8.

3. Flood A, Chung A, Parker $\mathrm{H}$ et al. The Use of Hand Grip Strength as a Predictor of Nutrition Status in Hospital Patients. Clin Nutr. 2014 Feb;33(1):106-14.

4. Yang L, Koyanagi A, Smith L et al. Hand Grip Strength and Cognitive Function Among Elderly Cancer Survivors. PLOS ONE. 2018 Jun 4;13(6):1-12.

5. De S, Sengupta P, Maity P et al. Effect of Body Posture on Hand Grip Strength in Adult Bengalee Population. Journal of Exercise Science and Physiotherapy. 2011;7(2):79-88.

6. Oseloka IA, Bello BM, Oliver HW et al. Association Of Handgrip Strength With Body Mass Index Among Nigerian Students. In 2014.

7. Hall J. Metabolism and Temperature Regulation. In: Guyton and Hall Textbook of Medical Physiology. 13th ed. Philidelphia: Elsevier; 2016. p. 887-902.

8. Al-Asadi J. Handgrip Strength in Medical Students: Correlation with Body Mass Index and Hand Dimensions. Asian J Med Sci. 2018 Jan 1;9(1):21-6.

9. Dhananjaya J, Veena H, Mamatha B et al. Comparative Study of Body Mass Index, Hand Grip Strength and Handgrip Endurance in Healthy Individuals. Natl J Physiol Pharm Pharmacol. 2017;7(6):1.

10. Lad UP, Satyanarayana P, Shisode-Lad S et al. A Study on the Correlation Between the Body Mass Index (BMI), the Body Fat Percentage, the Handgrip Strength and the Handgrip Endurance in Underweight, Normal Weight and Overweight Adolescents. J Clin Diagn Res JCDR. 2013 Jan; 7(1):51-4.

11. Massy-Westropp NM, Gill TK, Taylor AW et al. Hand Grip Strength: Age and Gender Stratified Normative Data in a Population-Based Study. BMC Res Notes. 2011 Apr 14;4(1):127-31.

12. Carmelli D, Reed T. Stability and Change in Genetic and Environmental Influences on Hand-grip Strength in Older Male Twins. J Appl Physiol. 2000 Nov 1;89(5):1879-83. 
13. Bross R, Casaburi R, Storer T et al. . Androgen Effects on body Composition and Muscle Function: Implications for the Use of Androgens as Anabolic Agents in Sarcopenic States. Bailliere's Clinical Endocrinology and Metabolism. 1998;12(3):365-78.

14. Hammed Al, Obaseki CO. Interdependence of Body Mass Index with Handgrip Strength and Endurance Among Apparently Healthy Teenagers. Turk J Kinesiol. 2018 Mar 30;4(1):1-7.

15. Ravisankar $\mathrm{P}$, Madanmohan, Udupa $\mathrm{K}$ et al. Correlation between Body Mass Index and Blood Pressure Indices, Handgrip Strength and Handgrip Endurance in Underweight, Normal Weight and Overweight Adolescents. Indian J Physiol Pharmacol. 2005;49(4):455-61.

16. Liao K. Hand Grip Strength in Low, Medium, and High Body Mass Index Males and Females. Middle East J Rehabil Health. 2016 Jan;3(1):1-7.

17. Das A, Dutta M. Correlation between Body Mass Index and Handgrip Strength and Handgrip Endurance Among Young Healthy Adults. Journal of Evidence based Medicine and Healthcare. 2015;2(27):3995-4001. 